\title{
O CONTRATO DE PLANO DE SAÚDE E SUA FUNÇÃO SOCIAL
}

\author{
HEALTH INSURANCE AGREEMENTS AND THEIR SOCIAL FUNCTION
}

Marta Rodrigues Maffeis Moreira*

\begin{abstract}
Resumo:
A Constituição Federal dispõe que a saúde é dever do Estado, facultando-se sua execução à iniciativa privada, que se dá de forma suplementar e por meio dos contratos de planos de saúde. Por se tratar de um serviço de relevância pública, as entidades particulares estão sujeitas ao controle e fiscalização por parte do Poder Público que, no presente caso, se dá pela Agência Nacional de Saúde (ANS). Por se tratar de contratos de consumo, as cláusulas contratuais devem observar as normas do Código de Defesa do Consumidor e sofrem controle por parte do Poder Judiciário, que as declara nulas, quando abusivas e contrárias à sua função social de oferecer um serviço de saúde adequado e seguro aos seus consumidores.

Palavras-chave: Serviço de saúde. Saúde suplementar. Contrato. Plano de saúde. Função social.
\end{abstract}

\begin{abstract}
:
The Brazilian Constitution disposes that health is a State duty, providing up its implementation to the private sector, which occurs in a supplemental form and through health insurance agreements. Due to the relevant public service, private entities are subject to control and surveillance by the Government which, in this case, is made by the National Health Agency. As it is about consumer contracts, clauses must regard the standards of the Consumer Protection Code and undergo control by the courts, which may declares them void, if abusive and contrary to the social function of providing an adequate and safe health service to consumers.
\end{abstract}

Keywords: Health service. Supplementary health. Contract. Health insurance. Social function.

\section{Introdução}

O presente estudo tem por objetivo analisar os contratos de plano de saúde e o efetivo cumprimento da função social. Para tanto, de início mostra-se necessário contextualizar o direito à saúde no ordenamento jurídico brasileiro, direito esse que foi elevado a direito social fundamental pela Constituição Federal de 1988.

O constituinte tomou a saúde como dever do Estado e estabeleceu um modelo básico de organização, consistente no Sistema Único de Saúde. Entretanto, não afastou a iniciativa privada da atividade de prestação da saúde, ao contrário, acolheu,

* Professora Doutora da Faculdade de Direito de Ribeirão Preto da Universidade de São Paulo; Juíza de Direito do Estado de São Paulo. 
podendo essa participação se dar de forma complementar, quando as entidades públicas firmam contratos ou convênios com o Poder Público a fim de oferecer serviços de forma complementar àqueles que não são oferecidos pela Administração.

Ainda, a iniciativa privada participa também de forma suplementar, por meio dos contratos de planos de saúde oferecidos pelas operadoras aos consumidores. Trata-se de contrato de consumo, cujas regras estão insculpidas na Lei n. 9.656/98, que devem ser lidas acompanhadas das normas do Código de Defesa do Consumidor.

Assim como os contratos em geral, os contratos de plano de saúde devem cumprir a função social de prestar o serviço de saúde de forma adequada e correta do ponto de vista técnico. Por conter muitas vezes cláusulas abusivas, que colocam o consumidor em manifesta desvantagem, o Poder Judiciário é chamado a corrigir as distorções, reequilibrando a relação entre operadoras e consumidores. Ainda, a Agência Nacional de Saúde desempenha papel importante no controle da função social dos contratos de saúde na medida em que busca a adequação dos vários contratos às suas normas administrativas, culminando por excluir determinados planos do mercado de consumo.

\section{Contextualização da saúde no ordenamento jurídico brasileiro}

O bem jurídico saúde foi contemplado na Constituição Federal de 1988 como um direito fundamental social. ${ }^{1}$

$\mathrm{O}$ art. $6^{\circ}$ da Carta Magna prevê expressamente a existência de direitos fundamentais sociais, dentre eles a saúde, os quais têm aplicação imediata, nos termos do art. $5^{\circ}, \S 1^{\circ}$, assim como os outros direitos e deveres individuais e coletivos (Capítulo I do Título I).

Art. $6^{\circ}$ : São direitos sociais a educação, a saúde, a alimentação, o trabalho, a moradia, o lazer, a segurança, a previdência social, a proteção à maternidade e à infância, a assistência aos desamparados, na forma desta Constituição. (grifo nosso).

\footnotetext{
A Carta Magna de 1988 foi a primeira a tratar a saúde como direito fundamental da pessoa. As outras Constituições apenas traziam questões esparsas sobre a saúde. A Constituição de 1824, em seu art. 179, XXXI, referia-se à proteção de "socorros públicos"; a Constituição anterior dava competência à União para legislar sobre defesa e proteção da saúde, no sentido de organização administrativa de combate às endemias e epidemias. Nesse sentido, MENDES, Gilmar Ferreira. Curso de direito constitucional. 6. ed. São Paulo: Saraiva, 2011. p. 685; SILVA, José Afonso. Comentário contextual à constituição. 7. ed. Malheiros: São Paulo, 2010. p. 781.
} 
Nesse sentido, todos os seres humanos, em caso de doença, têm direito a um tratamento condigno de acordo com o estado atual da Ciência Médica, independentemente de sua situação econômica. ${ }^{2}$

A Constituição Federal declara a saúde "direito de todos e dever do Estado, garantido mediante políticas sociais e econômicas que visem à redução do risco de doença e de outros agravos e ao acesso universal e igualitário às ações e serviços para sua promoção, proteção e recuperação" - serviços e ações que são de "relevância pública" (arts. 196 e 197).

Para Silva, ${ }^{3}$ o art. 196 apresenta, de forma expressa, duas vertentes.

A primeira ao estabelecer a saúde como direito, que tem por destinatário uma coletividade formada por brasileiros e estrangeiros residentes no país. Daí seu significado de universalização, o qual é reforçado ao prever o acesso igualitário às ações e serviços de saúde. A segunda vertente se refere à obrigação correspondente que cabe ao Estado, conforme se lê no texto, que a saúde é dever do Estado, no qual se englobam as pessoas jurídicas de direito público, União, Estados, Distrito Federal e Municípios, que podem agir tanto de forma direita, como por meio da Administração Pública indireta. ${ }^{4}$

Segundo Canotilho e Moreira, o direito à saúde comporta dois aspectos, um de natureza negativa, na medida em que abarca o direito de exigir do Estado e de terceiros que se abstenham da prática de qualquer ato que prejudique a saúde; outro, de natureza positiva, consistente no direito às medidas e prestações estaduais para prevenção de doenças e seu tratamento. ${ }^{5}$

Ao ser elevado à categoria dos direitos fundamentais sociais, as controvérsias que se referem à prestação da saúde devem ser resolvidas partindo-se do texto constitucional e da maneira como ele consagra o direito fundamental da saúde, além das especificidades do caso concreto. ${ }^{6}$

E o texto constitucional referente ao direito à saúde está inserido no título VIII que cuida "da ordem social" e no capítulo II, "da seguridade social". A saúde, portanto, é um direito social fundamental vinculado à seguridade social, que "compreende um

SILVA, José Afonso da. Comentário contextual à constituição. 7. ed. São Paulo: Malheiros, 2010. p. 187. SILVA, José Afonso da. Comentário contextual à constituição. 7. ed. São Paulo: Malheiros, 2010. p. 782.

4 Menciona o autor, ainda, que o dever se cumpre pelas prestações de saúde, que se materializam pelas políticas públicas sociais e econômicas que visem tanto a cura como a prevenção de doenças. Essas políticas se efetivam pela execução de ações e serviços de saúde que visam não apenas a cura de doenças, mas especialmente a prevenção "que visem à redução do risco de doença e de outros agravos". O texto constitucional sobressalta a proteção de uma vida humana saudável, como um direito fundamental.

5 CANOTILHO, José Joaquim Gomes; MOREIRA, Vital. Constituição da república portuguesa anotada. 1. ed. São Paulo: Revista dos Tribunais, 2014. v. 1, p. 342.

6 MENDES, Gilmar Ferreira; BRANCO, Paulo Gustavo. Curso de direito constitucional. 6. ed. São Paulo: Saraiva, 2011. p. 685. 
conjunto integrado de ações de iniciativa dos Poderes Públicos e da sociedade, destinadas a assegurar os direitos relativos à saúde, à previdência e à assistência social" (art. 194).

Fazer parte da Seguridade Social significa estar sob a regência dos princípios insculpidos no parágrafo único daquele dispositivo legal, ${ }^{7}$ quais sejam, universalidade de cobertura (universalidade objetiva) e do atendimento (universalidade subjetiva), da uniformidade ou equivalência dos benefícios, da unidade de organização, da descentralização da gestão administrativa, do caráter democrático, com participação de trabalhadores, empregadores, aposentados e Governo nos seus órgãos colegiados e da solidariedade financeira, porque será financiada por toda a sociedade, de forma direta ou indireta. $^{8}$

Tratando-se de um dever do Estado, a saúde deve ser oferecida por meio de serviço público e a Constituição Federal estabeleceu um modelo básico de organização da saúde, consistente no sistema único de saúde.

Nos termos do art. 198 da Constituição Federal o Sistema Único de Saúde - SUS - é integrado por uma rede regionalizada e hierarquizada de instituições e órgãos públicos federais, estaduais e municipais, da Administração direita e indiretas das fundações voltada às ações e serviços de saúde. Possui como princípios a descentralização, com direção única em cada esfera de governo; o atendimento integral, com prioridade para as atividades preventivas, sem prejuízo dos serviços assistenciais e a participação da comunidade.

O art. 198 define, de forma ampla, as atribuições do SUS, atribuições essas que serão mais especificadas pelas Leis ns. 8.142/90 e 8.080/90.

Diante do caráter regionalizado do SUS, a competência para cuidar da saúde foi definida como comum aos entes da Federação. O art. 23, II da Constituição estabelece que União, Estados, Distrito Federal e Municípios são responsáveis de forma solidária pela saúde.

Daí a importância do financiamento, previsto no art. 198, § $1^{\circ}$ da Carta Magna, que estabelece que o financiamento do SUS será efetivado por meio de recursos do orçamento da seguridade social, da União, dos Estados, do Distrito Federal e dos Municípios, além de ouras fontes. ${ }^{9}$

7 Embora o parágrafo único do art. 194 mencione que a Seguridade Social se organiza com base "nos seguintes objetivos", trata-se, na verdade, de princípios, pois é certo que a Seguridade Social pode se organizar para atingir objetivos, mas nenhum daqueles incisos contém objetivo a ser atingido, mas princípios orientadores, regentes, da organização da Seguridade Social. Nesse sentido, SILVA, José Afonso da. Comentário contextual à constituição. 7. ed. São Paulo: Malheiros, 2010. p. 774.

8 Esses princípios serão tratados mais adiante.

9 Por "outras fontes" consideram-se os recursos provenientes de: serviços que possam ser prestados sem prejuízo da assistência à saúde; ajudas, contribuições, doações e donativos; alienações patrimoniais e rendimentos de capital; taxas, multas, emolumentos e preços públicos arrecadados no âmbito do Sistema 
$\mathrm{O}$ art. 55 ADCT dispõe que "até que seja aprovada a lei de diretrizes orçamentárias, trinta por cento, no mínimo, do orçamento da seguridade social, excluído o seguro-desemprego, serão destinados ao setor de saúde".

A Emenda Constitucional n. 29/2000 buscou dar um norte ao assunto, ao estabelecer recursos mínimos para o financiamento das ações e serviços públicos de saúde. Também a redação do art. 77 ADCT foi alterada pela EC n. 29/2000 para que fossem definidos alguns critérios básicos nesse sentido. ${ }^{10}$

Entretanto, ao contrário do previsto no art. $198, \S 3^{\circ}$ da CF, esses dispositivos ainda não foram regulamentados. Há tentativas de se definir o que se deve entender por "ações e serviços de saúde" para se evitar abusos e desvio da aplicação e recursos mínimos na saúde, diante de sua forte imprecisão.

Mendes ${ }^{11}$ sustenta que o art. 196 da CF pode levar ao entendimento de que se tratam todas as ações que têm por objetivo a redução do risco de doença e outros agravos e o acesso universal e igualitário às ações e serviços para sua promoção, proteção e recuperação. O art. 197 ainda ressalta que essas ações são de "relevância pública".

Entretanto, apesar de a saúde ser um dever do Estado, a Constituição Federal não afastou a participação da iniciativa privada, ao contrário, acolheu-a, uma vez que seus arts. 197 e 199 fazem referência expressa à participação privada no sistema público de saúde, participação essa que deverá se dar de forma complementar. ${ }^{12}$

Art. 197. São de relevância pública as ações e serviços de saúde, cabendo ao Poder Público dispor, nos termos da lei, sobre sua regulamentação, fiscalização e controle, devendo sua execução ser feita diretamente ou através de terceiros e, também, por pessoa física ou jurídica de direito privado.

Art. 199. A assistência à saúde é livre à iniciativa privada. $\S 1^{\circ}$ - As instituições privadas poderão participar de forma complementar ao sistema único de saúde, segundo diretrizes

Único de Saúde; e rendas eventuais; e rendas eventuais, inclusive comerciais e industriais (Lei n. 8.080/90).

10 MENDES, Gilmar Ferreira; BRANCO, Paulo Gustavo. Curso de direito constitucional. 6. ed. São Paulo: Saraiva, 2011. p. 690.

11 MENDES, Gilmar Ferreira; BRANCO, Paulo Gustavo. Curso de direito constitucional. 6. ed. São Paulo: Saraiva, 2011. p. 691. Mencionam os autores que o Conselho Nacional de Saúde editou a Resolução n. 322/2003, na tentativa de definir "ações e serviços de saúde", com o objetivo de evitar que fossem computados aos gastos mínimos com saúde custeios com ações estranhas a essa área. Essa Resolução foi impugnada por meio de ação direta de inconstitucionalidade, sustentando-se que o Conselho Nacional de Saúde teria violado o art. $24 \mathrm{CF}$. Entretanto, não foi conhecida pelo STF, que entendeu que se tratava de eventual ofensa indireta à Carta Constitucional, uma vez que o ato impugnado deveria ser confrontado com as leis que o previra, - Leis ns. 8.080/90 e 8.142/90 - o que não poderia ocorrer em sede de ação direta de inconstitucionalidade.

12 SCHULMAN, Gabriel. Planos de saúde: saúde e contrato na contemporaneidade. Rio de Janeiro: Renovar, 2009. p. 202-203. 
deste, mediante contrato de direito público ou convênio, tendo preferência as entidades filantrópicas e as sem fins lucrativos.

Embora o sistema único de saúde seja constituído como sistema público, a rede privada pode integrar o SUS, por meio de contratação ou convênio firmado com o Poder Público, de forma que "tanto a rede pública como a privada acabam por formar uma rede regional, para melhor adequação às particularidades locais, concretizando, com isso, diretrizes da própria Organização Mundial da Saúde, e observando um conjunto de princípios que regem o sistema - integralidade, igualdade e participação da comunidade". ${ }^{13}$

A possibilidade de prestação de serviços de saúde por meio de entidades privadas está prevista no art. 199 da Constituição Federal, o qual ressalta que essa prestação deve se dar "de modo complementar".

Dessa forma, a Constituição distingue entre serviços públicos de saúde e assistência à saúde, sendo esta última exercida por entidades de caráter privado, que participam de forma complementar ao sistema único de saúde. ${ }^{14}$

A doutrina diferencia entre os serviços prestados pelas entidades privadas fora do SUS, como atividade privada e aqueles prestados de forma auxiliar ao sistema de saúde. $^{15}$

A participação das instituições privadas deve observar os princípios norteadores e as normas do Sistema Único de Saúde quanto às condições para o seu funcionamento e é firmada por meio de contratos de direito público ou convênio.

De acordo com a Lei Orgânica da Saúde, art. $3^{\circ}$, as instituições privadas deverão firmar convênio, quando houver interesse comum em estabelecer parceria em prol da prestação de serviços, promoção da saúde à população, e contrato administrativo quando objeto do contrato for a mera compra de serviços. ${ }^{16}$

Parte da doutrina sustenta que a complementaridade da participação privada na saúde significa uma participação limitada.

Nesse sentido, Di Pietro ${ }^{17}$ entende que a participação de instituições privadas de forma complementar afasta a possibilidade de o contrato abranger o serviço de saúde como um todo, assumindo o particular a gestão de determinado serviço. O Poder Público poderia apenas contratar instituições privadas para prestar atividades-meio, como

\footnotetext{
13 MENDES, Gilmar Ferreira; BRANCO, Paulo Gustavo. Curso de direito constitucional. 6. ed. São Paulo: Saraiva, 2011. p. 693-694.

14 SILVA, José Afonso da. Comentário contextual à constituição. 7. ed. São Paulo: Malheiros, 2010. p. 788.

15 MENDES, Gilmar Ferreira; BRANCO, Paulo Gustavo. Curso de direito constitucional. 6. ed. São Paulo: Saraiva, 2011. p. 694

16 MENDES, Gilmar Ferreira; BRANCO, Paulo Gustavo. Curso de direito constitucional. 6. ed. São Paulo: Saraiva, 2011. p. 694-695.

17 DI PIETRO, Maria Sylvia Zanella. Direito administrativo. 25. ed. São Paulo: Atlas, 2012. p. 243.
} 
limpeza, vigilância, contabilidade, ou mesmo serviços técnico-especializados, como os inerentes aos hemocentros, realização de exames médicos, consultas etc.

Entretanto, essa não é a melhor interpretação ao se analisar os dispositivos da Constituição Federal que tratam da participação da iniciativa privada na prestação de serviço de saúde.

O $\S 1^{\circ}$ do art. 199, embora trate da assistência à saúde, expressa a possibilidade de participação complementar da iniciativa privada em relação a todo o sistema público de saúde.

\section{A saúde suplementar}

Como visto acima, o Sistema Único de Saúde tem como atribuições tanto a prestação de serviços públicos de saúde como ações de saúde, apontadas no art. 200 da CF e nos arts. $5^{\circ}$ e $6^{\circ}$ da Lei n. 8.080/90. Se a assistência prestada pela iniciativa particular deve ser complementar ao SUS, devem ser incluídas todas as atividades do SUS, englobando, portanto, o serviço de saúde de modo amplo.

A complementaridade da participação privada na prestação de serviços públicos ocorre por delegação de serviço público, com todas as consequências legais atinentes ao regime jurídico de sua prestação.

Paralelamente à saúde complementar, a Constituição Federal faculta a participação das entidades privadas na chamada saúde suplementar, sendo de rigor fazer sua devida diferenciação.

Por saúde complementar entende-se aquela em que as entidades particulares passam a integrar o sistema público de saúde, por meio de contratos de direito público ou convênios com o SUS, submetendo-se, assim, aos princípios e diretrizes que orientam o serviço público.

$\mathrm{O}$ atendimento complementar obedece a dispositivos formais de contratação e diretrizes, critérios e parâmetros estabelecidos pela política pública de saúde. Dizse complementar porque essa participação das entidades privadas no SUS só ocorrerá quando o sistema público não possuir meios para suprir as necessidades da população. ${ }^{18}$

Nesse sentido, o art. 24 da Lei n. 8.080/90:

$$
\begin{aligned}
& \text { Quando as suas disponibilidades forem insuficientes } \\
& \text { para garantir a cobertura assistencial à população de uma } \\
& \text { determinada área, o SUS poderá recorrer aos serviços } \\
& \text { ofertados pela iniciativa privada. }
\end{aligned}
$$

18 FIGUEIREDO, Leonardo Vizeu. Curso de saúde suplementar. 2. ed. Rio de Janeiro: Gen - Forense, 2012. p. 97. 
Parágrafo único: A participação complementar dos serviços privados será formalizada mediante contrato ou convênio, observadas, a respeito, as normas de direito público.

Paralelamente, a Constituição Federal em seu art. 199 assegurou que a exploração do serviço de saúde é livre à iniciativa privada. Em outras palavras, a Constituição admitiu que pessoas físicas e jurídicas de direito privado prestem o serviço de assistência à saúde mediante uma contraprestação dos beneficiários. Entretanto, como já se mencionou acima, por se tratar de um direito fundamental de relevância pública, as entidades privadas estão submetidas à regulamentação, fiscalização e controle do poder público.

Segundo Schulman, ${ }^{19}$ por "saúde suplementar" entende-se a esfera de atuação dos planos de saúde. Trata-se da prestação do serviço de saúde fora do âmbito do Sistema Único de Saúde, organizada pela intermediação de pessoas jurídicas especializadas, as operadoras de planos de saúde. Nesse sentido, não figuram como prestação no âmbito da saúde suplementar os contratos de direito público ou convênios entre hospitais ou serviços privados e o SUS, nem o atendimento mediante pagamento direto pelo paciente.

Essa assistência à saúde praticada pelas entidades privadas e financiada diretamente pelo beneficiário caracteriza o setor da saúde suplementar. Assim, ocorre, neste caso, um regime participativo do particular no serviço de saúde, o que caracteriza essa atividade como econômica em sentido estrito, e regulamentada, exclusivamente por normas e regras de direito privado. ${ }^{20}$

Entretanto, em que pese os serviços de assistência suplementar à saúde ser atividade típica de mercado, uma vez que as ações e serviços de saúde são de relevância pública, nos termos do art. 197 da CF, as entidades privadas ficam inteiramente sujeitas a regulamentação, fiscalização e controle do Poder Público. ${ }^{21}$ Por isso, o direito de saúde suplementar é ramo do direito que se fundamenta tanto em normas de direito público como privado, "visando disciplinar as relações multilaterais entre o Estado, os agentes econômicos, os prestadores de serviços médicos e os consumidores, de um setor específico de nossa economia, a sabe, o mercado de assistência privada à saúde". ${ }^{22}$

19 SCHULMAN, Gabriel. Planos de saúde: saúde e contrato na contemporaneidade. Rio de Janeiro: Renovar, 2009. p. 201-202.

20 FIGUEIREDO, Leonardo Vizeu. Curso de direito de saúde suplementar. 2. ed. Rio de Janeiro: Gen Forense, 2012. p. 97-98; SCHULMAN, Gabriel. Planos de saúde: saúde e contrato na contemporaneidade. Rio de Janeiro: Renovar, 2009. p. 202-203.

${ }_{21}$ SILVA, José Afonso da. Comentário contextual à constituição. 7. ed. São Paulo: Malheiros, 2010. p. 783.

22 FIGUEIREDO, Leonardo Vizeu. Curso de direito de saúde suplementar. 2. ed. Rio de Janeiro: Gen Forense, 2012. p. 7. 
A saúde suplementar constitui um ramo autônomo do Direito, ligado mais especificamente ao Direito Econômico ${ }^{23}$ e possui alguns princípios importantes para a análise dos contratos de planos de saúde. ${ }^{24}$

\section{Princípio da defesa do mercado}

As normas de direito de saúde suplementar devem primar pela manutenção da higidez econômico-financeira do mercado e pela preservação dos agentes econômicos que nela operam.

Como a Constituição Federal, em seu $\S 2^{\circ}$ do art. 199, veda "a destinação de recursos públicos para auxílios ou subvenções às instituições privadas com fins lucrativos", a prestação dos serviços da assistência à saúde é financiada exclusivamente por recursos privados, o que lhe dá a tônica de atividade econômica em sentido estrito.

Para garantir a assistência privada aos consumidores, há que se disciplinar um conjunto normativo que viabilize a atividade e maximize a obtenção de resultados financeiros, buscando, assim, a concorrência saudável entre os participantes (art. 170, IV da $\mathrm{CF}$ ) e a melhor oferta de serviço aos usuários, que são os consumidores (art. 170, V $\mathrm{CF})$.

\section{Princípio da defesa do consumidor}

As normas jurídicas de saúde suplementar devem visar a qualidade técnica do serviço oferecido, a fim de que as operadoras ofereçam serviços de saúde que alcancem seus fins legais e contratuais, com preços adequados e justos, o que justifica seu controle por meio do Poder Público.

Ainda, busca-se o acesso igualitário ao plano, bem como a garantia da disponibilização de atendimento médico eficiente.

\section{Princípio da efetiva tutela da saúde}

As normas de direito de saúde suplementar devem garantir ao consumidor que os atendimentos médicos disponibilizados pelos agentes econômicos realmente constituam um conjunto de ações efetivamente capazes de garantir tanto o restabelecimento da saúde quanto a prevenção de doenças.

23 Por essa razão não se adentrará em minúcias específicas do Direito Econômico, por não ser o escopo desse trabalho.

24 FIGUEIREDO, Leonardo Vizeu. Curso de direito de saúde suplementar. 2. ed. Rio de Janeiro: Gen Forense, 2012. p. 19-21. 
A disponibilização de serviços de planos privados sem o mínimo padrão de qualidade técnica, ainda que por preços módicos, coloca em risco a saúde do consumidor, violando a norma do art. $4^{\circ}$ do Código de Defesa do Consumidor, e possibilitando a intervenção estatal por meio da ANS, que muitas vezes determina o encerramento do plano.

O modelo precursor da assistência à saúde no Brasil foi o Decreto-Lei n. 37 de 21 de novembro de 1966, que organizou a prestação do serviço através da iniciativa privada em torno dos seguros-saúde e planos de saúde, cabendo à Lei n. 9.656/98 importantes modificações ao sistema legal, normativo e fiscalizador, como se verá a seguir. $^{25}$

Esse modelo estruturou o sistema nacional de seguros privados, ao introduzir duas modalidades básicas de assistência à saúde: o seguro e a medicina de grupo.

O seguro-saúde é típico contrato de seguro, que tem por finalidade a cobertura aos riscos de assistência médica e hospitalar. Nos termos dos arts. 129 e 130 do decreto cabe ao segurado o direito de livre escolha do médico e do hospital e à sociedade seguradora o pagamento ou reembolso das despesas de tratamento.

$\mathrm{O}$ art. 135 admitiu também a chamada medicina de grupo, autorizando as entidades sem fins lucrativos, organizadas por profissionais médicos e paramédicos ou por estabelecimentos hospitalares, a operar sistemas próprios de pré-pagamento.

Nesse caso, o beneficiário recebe diretamente do empreendedor uma determinada assistência à sua saúde, cabendo-lhe, em contraprestação, um pagamento em dinheiro, em regra, periódico. Geralmente o sujeito ativo da contratação funciona como organizador do serviço de saúde, subcontratando ou delegando a terceiros a efetiva prestação do serviço. De um lado há o contrato celebrado pelo beneficiário com o organizador e, de outro, há diversas vinculações jurídicas entre o organizador e os efetivos prestadores dos serviços (médico, hospitais, laboratórios).

Embora não sejam seguradoras, as entidades praticantes da medicina de grupo foram submetidas às regras e à fiscalização dos órgãos do sistema securitário, nos termos do art. 135 do Decreto-Lei, sendo eles o Conselho Nacional de Seguros Privados (CNSP) e a Superintendência dos Seguros Privados (Susep).

Como não fora estabelecida a forma societária, participaram da medicina de grupo as cooperativas, nos termos da Lei n. 5.764/71. ${ }^{26}$

\footnotetext{
25 PASQUALOTO, Adalberto. A regulamentação dos planos e seguros de assistência à saúde: uma interpretação construtiva. In: MARQUES, Claudia Lima et al. Saúde e responsabilidade: seguros e planos de assistência privada à saúde. São Paulo: Revista dos Tribunais, 1999. p. 39-45.

26 O mais conhecido grupo de cooperativa é o Sistema Unimed, sendo o precursor de todas as empresas operadoras e planos de saúde. Nesse sentido, BOTTESINI, Maury Ângelo; MACHADO, Mauro Conti. Lei dos planos e seguros de saúde. São Paulo: Revista dos Tribunais, 2003. p. 45.
} 
Entretanto, esse sistema apresentou diversas falhas.

O Decreto-Lei prescreveu o prazo de 120 dias para a regulamentação do seguro-saúde, fato esse que nunca ocorreu, dando margem a abusos praticados pelas entidades em detrimento dos segurados diante da ampla liberdade que os operadores dos contratos gozavam.

Além disso, se a redação original do art. 135 do referido decreto dispunha que as entidades de medicina pré-paga não podiam ter como fim o lucro, a Portaria n. 3.286/86 do Ministério do Trabalho franqueou a elas o recebimento de uma contraprestação pecuniária preestabelecida. ${ }^{27}$

As seguradoras ligadas a grupos financeiros sentiam a força das cooperativas organizadas por médicos e seus planos de seguros médico-hospitalares foram minguando até desaparecer quase por completo.

Por volta de 1990 a FENASEG (Federação Nacional das Seguradoras) se movimentou para reestruturar o mercado de seguro-saúde, o que ocorreu com a edição da Lei n. 9.656/98 a qual sofreu diversas modificações pela Medida Provisória n. 2.177 de 24.08.2001, reeditada 44 vezes.

A Lei n. 9.656/98 dispôs-se a disciplinar os vários empresários que exploram os serviços de seguros-saúde, planos de saúde e assistência médica e compreende a prevenção da doença e a recuperação, a manutenção e a reabilitação da saúde, fins perseguidos pelas instituições privadas abrangidas pela regulamentação legal, que se organizam, preferencialmente, como operadoras de planos e seguradoras.

Operadoras de planos privados de assistência à saúde são pessoas jurídicas de direito privado, com liberdade de forma societária, que prestam serviços próprios ou através de terceiros, mediante contraprestações pecuniárias.

As seguradoras devem se organizar na forma de sociedades anônimas nos moldes do Decreto-Lei n. 73. Sua finalidade é a cobertura de riscos de assistência à saúde, mediante a livre escolha pelo segurado do prestador do serviço e o reembolso das despesas.

A lei também se aplica à autogestão de forma mais parcial, sem a cobertura universal das doenças relacionadas na Classificação Internacional (art. 10). A autogestão ocorre em grupos fechados, de acesso restrito aos empregados, funcionários ou associados da entidade promotora.

O Decreto-Lei dispensou tratamento mais brando, em seu art. $143, \S 1^{\circ}$, excluindo-a expressamente do regime legal, apenas facultando ao CNSP o exercício de fiscalização.

27 Referida Portaria definiu "empresa de medicina de grupo como toda aquela pessoa jurídica de direito privado, organizada de acordo com as leis do país, que se dedique a assegurar a assistência médica ou hospitalar e ambulatorial, mediante uma contraprestação pecuniária preestabelecida”. 
Por fim, as cooperativas de serviços médicos, podem ser inseridas no art. $1^{\circ}$, $\S 1^{\circ}$, inc. I da Lei n. 9.656/98 como operadoras de planos privados de assistência à saúde.

Atualmente a estruturação da saúde suplementar no Brasil é organizada pelas operadoras de planos de saúde, que estão vinculadas à ANS (Agência Nacional de Saúde Suplementar) e se submetem à Lei dos Planos e Seguros de Saúde, Lei n. 9.656/98.

Na função de regulamentação e fiscalização exercida pela ANS importante mencionar a Resolução Normativa n. 259/2011 que dispõe sobre a garantia de atendimento dos beneficiários de plano privado de assistência à saúde e altera a Instrução Normativa IN n. 23 de $1^{\circ}$ de dezembro de 2009, da Diretoria de Normas e Habilitação dos Produtos - DIPRO.

No capítulo II da Resolução, dispõe a ANS sobre as garantias de atendimento ao beneficiário, estabelecendo-se os prazos máximos para atendimento (arts. $2^{\circ}$ e $3^{\circ}$ ); a garantia de atendimento na hipótese de indisponibilidade ou inexistência e prestador no município pertencente à área geográfica de abrangência e à área de atuação do produto $\left(\operatorname{arts.} 4^{\circ}\right.$ a $6^{\circ}$ ); garantia de transporte em casos especificados em lei (arts. $7^{\circ}$ e $8^{\circ}$ ); garantia de reembolso em casos especificados em lei (art. $9^{\circ}$ ).

No site da ANS (http://www.ans.gov.br) encontra-se a seguinte prescrição:

"Planos de Saúde com Comercialização Suspensa.

Planos de saúde com comercialização suspensa para novos beneficiários e Planos de saúde com comercialização reativada.

A ANS faz o acompanhamento da garantia do atendimento do beneficiário e dos prazos máximos desse atendimento para consultas, exames e cirurgias. Este monitoramento junto às operadoras de planos de saúde é permanente e contínuo e a divulgação dos dados apurados é feita pela ANS a cada três meses.

A suspensão da comercialização dos planos mais reclamados ocorre pelo descumprimento reiterado por parte das operadoras dos prazos máximos para realização de consultas, exames e cirurgias e por negativa de cobertura assistencial aos beneficiários de planos de assistência médica e odontológica.

Metodologia:

O Monitoramento é feito com base nas reclamações recebidas pela ANS e na quantidade de beneficiários das operadoras dos planos de saúde, que são analisadas conforme o tipo de mercado em que atuam.

Processada de forma eletrônica e sistematizada - segundo critérios estritamente objetivos, pré-definidos e publicados nos normativos - a análise comparativa apresenta aquelas operadoras que estiverem na pior situação possível nos últimos dois períodos e têm suspenso o direito de comercializar os produtos mais reclamados até que apresentem resultados melhores, alcançando, então, a reativação.

Consequências da Suspensão da Comercialização: 
Quando uma operadora de plano de saúde está com produto com comercialização suspensa em decorrência do Monitoramento da Garantia de Atendimento:

- não poderá registrar nenhum novo produto que seja análogo aos que estiverem na lista de suspensão (Vide $\S 3^{\circ}$ do art. 12-A da RN n. 259);

- não poderá receber novos beneficiários nos planos de saúde com comercialização suspensa por esse motivo (com exceção de novo cônjuge ou filho e de ex-empregados demitidos ou aposentados, na forma da regulamentação)."

\section{Os contratos de planos de saúde e sua função social}

Os contratos de plano de saúde são aqueles em que a operadora do plano se obriga frente ao consumidor em cobrir os riscos de assistência à sua saúde, de forma que prestará serviços médicos hospitalares e/ou odontológicos ou reembolsará eventuais despesas do consumidor em casos de urgência. Em contrapartida, o consumidor possui a obrigação de pagar o valor contratado à prestadora.

Trata-se de contratos de longa duração, de trato sucessivo e visam uma obrigação de resultado, qual seja, o reembolso de valores pagos pelo consumidor, a cobertura de serviços médicos, exames e/ou medicamentos. ${ }^{28}$

Os contratos de planos de saúde possuíam a característica de serem totalmente adesivos, o que significa dizer que a operadora do plano designava unilateralmente todas as cláusulas do contrato, sem qualquer participação do usuário, obrigando-o a aceitar as coberturas dispostas naquele documento. A partir da Lei n. 9.656/98, que regulamenta os planos de saúde, buscou-se reduzir a discricionariedade das operadoras ao oferecerem seus planos diante da hipossuficiência técnica do usuário. ${ }^{29}$

Dessa maneira, a lei define as cláusulas básicas dos contratos de plano de saúde que não podem ser afastadas pela operadora, além de outras normas que serão oportunamente discutidas neste artigo. Entretanto, ainda podem ser considerados contratos de adesão, visto que não há discussão bilateral das cláusulas, apenas a operadora redige o contrato e o consumidor concorda ou não com os termos.

O contrato deve trazer explicitamente todas as condições, preços, vigência, os eventos cobertos pelo contrato, a área de abrangência, enfim, todas as informações necessárias para que o usuário consumidor consiga utilizar o serviço sem ser surpreendido

28 BONIZZATO, Luigi; MARTINS, Flávio Alves. Saúdes pública e privada e relações de consumo: uma análise constitucional e civilística de responsabilidades estatais, pré e pós-contratuais no Brasil. Revista de Direito do Consumidor, São Paulo, v. 23, n. 96, p. 109-138, nov./dez. 2014.

29 RIZZARDO, Arnaldo. Contratos. 13. ed. Rio de Janeiro: Gen - Forense, 2013. p. 885. 
com uma negativa de atendimento por ausência de explicações no contrato. A Lei n. 9.656/98 obriga a exposição de tais dispositivos uma vez que as operadoras possuem a função suplementar de auxílio no serviço público de saúde, entretanto são empresas de direito privado que, como regra, possuem como objetivo primeiro a lucratividade de sua atividade. Dessa maneira, uma vez que o consumidor não possui o conhecimento técnico para analisar as cláusulas contratuais que são escritas muitas vezes em linguagem médica e de difícil compreensão, há a necessidade dessa proteção legal a fim de que ele seja claramente informado de todos os seus direitos e deveres perante a operadora em uma linguagem simples e precisa. ${ }^{30}$ Essa informação é repassada para que o consumidor saiba quais são os seus direitos contratuais, mas também para evitar que gastos excessivos sejam suportados pelos consumidores a fim de garantir os fins lucrativos da empresa.

Nesse sentido, considerando o contrato de plano de saúde um contrato respaldado pelo Direito do Consumidor, ${ }^{31}$ as condutas necessárias para esses contratos em geral, também devem aparecer nesse contrato em especial, quais sejam, condutas de lealdade, informação, lisura, cooperação, boa-fé. A súmula do STJ de n. $469^{32}$ determina a aplicação do CDC nos contratos de plano de saúde, uma vez que há nitidamente a presença de uma parte vulnerável, seja econômica, seja tecnicamente, que necessita dessa proteção legal para garantir o equilíbrio contratual entre as partes. O contrato de plano de saúde se subsume aos requisitos para uma relação de consumo, quais sejam, a existência de um fornecedor que presta um serviço de natureza securitária mediante remuneração (art. $3^{\circ}$, “caput" e $\S 2^{\circ}, \mathrm{CDC}$ ) e um consumidor, pessoa física ou jurídica, que adquire esse serviço (art. $2^{\circ}, \mathrm{CDC}$ ), sendo o serviço em si o objeto da relação jurídica.

Outra norma do CDC aplicada a esses contratos é a imposição de uma responsabilidade solidária de todos os fornecedores da cadeia, inclusive das operadoras

30 LOPES, José Reinaldo de Lima. Consumidores de seguros e planos de saúde (ou, doente também tem direitos). In: MARQUES, Claudia Lima; LOPES, José Reinaldo de Lima; PFEIFFER, Roberto Augusto Castellanos. Saúde e responsabilidade: seguros e planos de assistência privada à saúde. São Paulo: Revista dos Tribunais, 1999. p. 29.

31 LOPES, José Reinaldo de Lima. Consumidores de seguros e planos de saúde (ou, doente também tem direitos). In: MARQUES, Claudia Lima; LOPES, José Reinaldo de Lima; PFEIFFER, Roberto Augusto Castellanos. Saúde e responsabilidade: seguros e planos de assistência privada à saúde. São Paulo: Revista dos Tribunais, 1999. p. 29.

32 “Aplica-se o Código de Defesa do Consumidor aos contratos de plano de saúde". O art. $3^{\circ}$ da Lei n. 9.656/98, cuja eficácia foi suspensa pela MP n. 2.177-44/2001, tinha redação semelhante. 
para garantir a qualidade do serviço. ${ }^{33}$ Assim, a prestadora é responsável solidariamente com o fornecedor direto, seja o médico, hospital ou clínica. ${ }^{34}$

Sendo esse um contrato de trato sucessivo, os contratantes se preocupam principalmente com a obrigação final da prestadora, qual seja, a efetiva cobertura dos riscos e eventos danosos que venham a acontecer à sua saúde. Assim, o contrato também é aleatório, já que impossível definir quando e se acontecerá esse evento, que é a doença do segurado. ${ }^{35}$

A incerteza é em relação ao momento em que a doença ocorrerá, mas contratualmente devem ser definidas as maneiras como a prestação ocorrerá, evitando prestações desqualificadas e inseguras para o consumidor. Trata-se de contratos de "contratos cativos de longa duração", em que os contratantes manterão relações de convivência e dependência com as prestadoras por anos, podendo ou não usufruir dos serviços, mas sempre adimplindo as mensalidades. ${ }^{36}$

Esses contratos possuem as peculiaridades da carência e da preexistência. A carência é o período logo após a celebração do contrato em que o consumidor terá a suspensão da cobertura de serviços de saúde, mesmo pagando os prêmios à prestadora. ${ }^{37}$ Isso ocorre porque as prestadoras são empresas que atuam no mercado e não podem arcar com ônus superiores aos quais o consumidor já se onerou, de forma a evitar também a quebra do princípio do equilíbrio econômico-financeiro. A carência será excluída em casos de emergência ou de urgência. ${ }^{38}$ A preexistência refere-se às doenças cujo portador

33 Art. 24. A garantia legal de adequação do produto ou serviço independe de termo expresso, vedada a exoneração contratual do fornecedor.

Art. 25. É vedada a estipulação contratual de cláusula que impossibilite, exonere ou atenue a obrigação de indenizar prevista nesta e nas seções anteriores.

$\S 1^{\circ}$ Havendo mais de um responsável pela causação do dano, todos responderão solidariamente pela reparação prevista nesta e nas seções anteriores.

$\S 2^{\circ}$ Sendo o dano causado por componente ou peça incorporada ao produto ou serviço, são responsáveis solidários seu fabricante, construtor ou importador e o que realizou a incorporação.

34 MARQUES, Claudia Lima. Contratos no código de defesa do consumidor. 6. ed. São Paulo: Saraiva, 2009. p. 511.

35 MARQUES, Claudia Lima. Contratos no código de defesa do consumidor: o novo regime das relações contratuais. 6. ed. São Paulo: Revista dos Tribunais, 2011. p. 518.

36 MARQUES, Claudia Lima. Contratos no código de defesa do consumidor: o novo regime das relações contratuais. 6. ed. São Paulo: Revista dos Tribunais, 2011. p. 105.

37 Resolução ANS n. 195. Art. $4^{\circ} \mathrm{O}$ contrato de plano privado de assistência à saúde individual ou familiar, poderá conter cláusula de agravo ou cobertura parcial temporária, em caso de doenças ou lesões preexistentes, nos termos da resolução específica em vigor, bem como a exigência de cumprimento de prazos de carência, nos termos da Lei n. 9.656, de 3 de junho de 1998.

Lei n. 9.656/98. Art. 12, V - quando fixar períodos de carência:

a) prazo máximo de trezentos dias para partos a termo;

b) prazo máximo de cento e oitenta dias para os demais casos;

c) prazo máximo de vinte e quatro horas para a cobertura dos casos de urgência e emergência.

38 Lei n. 9.656/98. Art. 35-C. É obrigatória a cobertura do atendimento nos casos: (Redação dada pela Lei n. 
já conhecia no momento da celebração do contrato, e que, portanto, são anteriores a ela. Nesse caso, o art. 11 da Lei n. 9.656/98 determina um prazo de carência de 24 meses. $^{39}$ É dever e representa a boa-fé do consumidor dar ciência à prestadora de sua doença preexistente antes da assinatura do contrato. ${ }^{40}$

Hoje no Brasil encontram-se mais de 1,2 mil empresas prestadoras de serviços de saúde. ${ }^{41}$ Elas são pessoas jurídicas de direito privado que operam planos de assistência à saúde e que se submetem à regulamentação da ANS com o objetivo de controlar o oferecimento do serviço, garantindo a eficácia e qualidade do mesmo. Também podem ser operadoras de planos de saúde as cooperativas médicas, bem como as entidades ou empresas que mantém sistemas de assistência à saúde, pela modalidade de autogestão ou de administração. Os arts. 10 e 12 da Lei n. 9.656/98 estabelecem o plano-referência para todas as operadoras, de forma que sem o oferecimento deste, a operadora não obterá o registro para funcionar legalmente. Esse plano deverá oferecer assistência médicoambulatorial e hospitalar de doenças que sejam reconhecidas pela Organização Mundial da Saúde, de forma que não poderá haver limitação para cobertura de consultas médicas ou de internações hospitalares, como determina a Súmula n. 302 do STJ, ${ }^{42}$ a operadora deverá cobrir despesas referentes a honorários médicos e exames complementares e reembolsar o usuário caso este utilize, em caso de urgência ou emergência, produtos contratados, mas indisponíveis pela operadora naquela situação. ${ }^{43}$ Será o consumidor do plano que

11.935, de 2009).

I - de emergência, como tal definidos os que implicarem risco imediato de vida ou de lesões irreparáveis para o paciente, caracterizado em declaração do médico assistente; (Redação dada pela Lei n. 11.935, de 2009).

II - de urgência, assim entendidos os resultantes de acidentes pessoais ou de complicações no processo gestacional; (Redação dada pela Lei n. 11.935, de 2009).

III - de planejamento familiar.

39 Art. 11. É vedada a exclusão de cobertura às doenças e lesões preexistentes à data de contratação dos produtos de que tratam o inciso I e o $\S 1^{\circ}$ do art. $1^{\circ}$ desta Lei após vinte e quatro meses de vigência do aludido instrumento contratual, cabendo à respectiva operadora o ônus da prova e da demonstração do conhecimento prévio do consumidor ou beneficiário.

40 BONIZZATO, Luigi; MARTINS, Flávio Alves. Saúdes pública e privada e relações de consumo: uma análise constitucional e civilística de responsabilidades estatais, pré e pós-contratuais no Brasil. Revista de Direito do Consumidor, São Paulo, v. 23, n. 96, p. 109-138, nov./dez. 2014. p. 122.

41 Disponível em: <http://www.ans.gov.br/images/stories/Plano_de_saude_e_Operadoras/Area_da_ Operadora/IDSS/listagem_resultados_idss_2104.pdf>. Acesso em: 9 mar. 2014.

42 Súmula 302 STJ: "É abusiva a cláusula contratual de plano de saúde que limita no tempo a internação hospitalar do segurado".

43 Art. 10: É instituído o plano-referência de assistência à saúde, com cobertura assistencial médicoambulatorial e hospitalar, compreendendo partos e tratamentos, realizados exclusivamente no Brasil, com padrão de enfermaria, centro de terapia intensiva, ou similar, quando necessária a internação hospitalar, das doenças listadas na Classificação Estatística Internacional de Doenças e Problemas Relacionados com a Saúde, da Organização Mundial de Saúde, respeitadas as exigências mínimas estabelecidas no art. 12 desta Lei, exceto: (...)

Art. 12: São facultadas a oferta, a contratação e a vigência dos produtos de que tratam o inciso I e o $\S 1^{\circ}$ 
optará no momento da contratação pelo plano que pretende assumir, de forma que a cada cláusula de itens adicionais na cobertura o preço poderá ser aumentado pela operadora. ${ }^{44}$

A partir da entrada das empresas privadas na prestação contratual do sistema de saúde pública criou-se a necessidade de que os princípios antes aplicados somente à relação existente entre Poder Público e cidadão usuário, sejam também aplicados na relação de prestação dos serviços privados, objetivando que a exploração econômica deste setor se paute na função social que é intrínseca ao serviço de saúde. ${ }^{45}$

Com o objetivo de equilibrar os interesses individuais e as necessidades coletivas e sociais, surgiu a funcionalização dos institutos jurídicos, decorrência da própria natureza da vida em sociedade, que torna indispensável a colaboração recíproca entre os seres humanos. Dessa maneira, seria legítima a inferência estatal para adaptar os institutos às exigências do bem comum. Nesse escopo, ganhou destaque a doutrina da função social, matriz filosófica apta a restringir o individualismo frente aos ditames do interesse coletivo.

Assim discorreu Reale sobre o tema da função social do contrato:

O que o imperativo da "função social do contrato" estatui é que este não pode ser transformado em um instrumento para atividades abusivas, causando dano à parte contrária ou a terceiros, uma vez que, nos termos do Art. 187, 'também comete ato ilícito o titular de um direito que, ao exercê-lo, excede manifestamente os limites impostos pelo seu fim econômico ou social, pela boa-fé ou pelos bons costumes'.

do art. $1^{\circ}$ desta Lei, nas segmentações previstas nos incisos I a IV deste artigo, respeitadas as respectivas amplitudes de cobertura definidas no plano-referência de que trata o art. 10, segundo as seguintes exigências mínimas: (Redação dada pela Medida Provisória n. 2.177-44, de 2001).

I - quando incluir atendimento ambulatorial:

cobertura de consultas médicas, em número ilimitado, em clínicas básicas e especializadas, reconhecidas pelo Conselho Federal de Medicina; (...)

II - quando incluir internação hospitalar:

cobertura de internações hospitalares, vedada a limitação de prazo, valor máximo e quantidade, em clínicas básicas e especializadas, reconhecidas pelo Conselho Federal de Medicina, admitindo-se a exclusão dos procedimentos obstétricos; (...)

VI - reembolso, em todos os tipos de produtos de que tratam o inciso I e o $\S 1^{\circ}$ do art. $1^{\circ}$ desta Lei, nos limites das obrigações contratuais, das despesas efetuadas pelo beneficiário com assistência à saúde, em casos de urgência ou emergência, quando não for possível a utilização dos serviços próprios, contratados, credenciados ou referenciados pelas operadoras, de acordo com a relação de preços de serviços médicos e hospitalares praticados pelo respectivo produto, pagáveis no prazo máximo de trinta dias após a entrega da documentação adequada; (...)

44 BOTTESINI, Maury Ângelo; MACHADO, Mauro Conti. Lei dos planos e seguros de saúde. São Paulo: Revista dos Tribunais, 2003. p. 99.

45 GLOBEKNER, Osmir Antônio. A saúde entre o público e o privado: o desafio da alocação social dos recursos sanitários escassos. Juruá: Curitiba, 2011. p. 154. 
Não há razão alguma para se sustentar que o contrato deva atender tão somente aos interesses das partes que o estipulam, porque ele, por sua própria finalidade, exerce uma função social inerente ao poder negocial que é uma das fontes do direito, ao lado da legal, da jurisprudencial e da consuetudinária. ${ }^{46}$

Dessa maneira, o contrato deixa de ter seu foco somente nos interesses individuais daqueles que contratam para combiná-los com os valores coletivos, de forma que haja um equilíbrio entre o que as partes autonomamente desejam com aquele contrato e quais seriam as decisões equitativas e que não ferem direitos de terceiros ou da coletividade.

O Código de Defesa do Consumidor foi a primeira tentativa de trazer à tona essa função social do contrato, ao proteger a vulnerabilidade do consumidor. Seu art. 47 invoca a interpretação contratual mais benéfica ao consumidor e o art. 51 trata da nulidade de cláusulas abusivas, reduzindo a autonomia da vontade entre as partes, visto que, na relação consumerista, uma delas é hipossuficiente e essa autonomia resta desequilibrada sem aquela proteção jurídica. Dessa forma, houve uma redução da liberdade contratual, principalmente daquele que antes possuía totalmente a liberdade de criar o conteúdo contratual, de forma que o consumidor apenas submetia-se a esse "poder". Para limitar essa liberdade novas obrigações foram inseridas no contrato, como, por exemplo, a proibição de romper o vínculo contratual se a escolha não for do consumidor ou colocada à sua disposição, valorizando, portanto, o tempo em que há o vínculo contratual. ${ }^{47}$ Outra maneira foi a já dita possibilidade de anulação de cláusulas consideradas abusivas, como as que permitem que o fornecedor altere o preço ou qualquer cláusula contratual de maneira unilateral.

Após o advento do Código de Defesa do Consumidor, o Código Civil de 2002, em seu art. 421, menciona expressamente a função social como limitadora da liberdade de contratar. Essa foi uma forma de expandir a aplicação da função social para os contratos em geral, e não mais apenas aos contratos consumeristas. Assim, o contrato, que possuía como princípio básico a relatividade dos efeitos, começa a ser analisado a partir da preocupação desses efeitos erga omnes. Nesse aspecto tem-se que o contrato não

46 REALE, Miguel. Função social do contrato. Disponível em: <http://www.miguelreale.com.br/artigos/ funsoccont.htm>. Acesso em: 12 mar. 2015.

47 MARQUES, Claudia Lima. Contratos no código de defesa do consumidor: o novo regime das relações contratuais. 6. ed. São Paulo: Revista dos Tribunais, 2011. p. 271.

Art. 54. Contrato de adesão é aquele cujas cláusulas tenham sido aprovadas pela autoridade competente ou estabelecidas unilateralmente pelo fornecedor de produtos ou serviços, sem que o consumidor possa discutir ou modificar substancialmente seu conteúdo. (...)

$\S 2^{\circ}$ Nos contratos de adesão admite-se cláusula resolutória, desde que a alternativa, cabendo a escolha ao consumidor, ressalvando-se o disposto no $\S 2^{\circ}$ do artigo anterior. 
deve apenas ter seu foco entre as partes contratantes, mas também se preocupar com os efeitos sociais, evitando que a contratação traga prejuízos para terceiros e para a sociedade em geral. Não é aceitável que o Estado, mesmo permitindo a participação de entidades privadas na administração pública, permita que a liberdade de contratação seja contrária ao bem estar da população e o interesse coletivo. ${ }^{48}$

No mesmo sentido, Tartuce defende que devem ser afastadas as cláusulas contrárias à ordem pública e que prejudiquem a igualdade substancial entre os contratantes. ${ }^{49}$

Em uma relação contratual, as partes são livres para contratar de acordo com a sua vontade, podendo regular o objeto e as condições em que irão realizar suas prestações e contraprestações. Entretanto, o Direito estabelece limitações internas e externas para os sujeitos, uma vez que podem existir partes hipossuficientes que precisam de proteção para não sofrer abusos contratuais e terceiros que não podem ser afetados por condutas que contrariem seus direitos. ${ }^{50}$ Por isso a relação contratual está sujeita ao princípio da boa-fé, confiança e eticidade, no âmbito interno, e ao princípio da função social do contrato, no âmbito externo.

Para discorrer sobre a função social dos contratos de plano de saúde, necessário será iniciar pela análise dessa função em contratos de adesão, nos quais estão inseridos os de plano de saúde.

A adesividade dos contratos é causada pela imposição contratual por uma das partes em relação às cláusulas e condições do negócio jurídico de forma que a outra parte não tenha permissão para alterar qualquer uma delas. Mesmo que haja imposição legal de algumas cláusulas, não foi a parte vulnerável quem atuou na composição da cláusula. Nesse caso, fica fortemente caracterizada a vulnerabilidade da parte que necessita contratar em face de outra que realiza toda a produção do contrato.

No caso dos contratos de plano de saúde, além da vulnerabilidade do consumidor, existe grande dependência dele face à prestadora, uma vez que aquele contrato será de extrema necessidade visto que a saúde pública não é fornecida corretamente e com qualidade pelo Poder Público. ${ }^{51}$ Sem compreender as cláusulas contratuais e necessitando contratar, o consumidor se vê convencido a contratar daquela maneira e só percebe que há

48 THEODORO JÚNIOR, Humberto. O contrato e sua função social. 3. ed. Rio de Janeiro: Forense, 2008. p. 34.

49 TARTUCE, Flávio. Função social dos contratos: do Código de Defesa do Consumidor ao Código Civil de 2002. São Paulo: Método, 2007. p. 261.

50 THEODORO JÚNIOR, Humberto. O contrato e sua função social. 3. ed. Rio de Janeiro: Forense, 2008. p. 110 .

51 TARTUCE, Flávio. Função social dos contratos: do Código de Defesa do Consumidor ao Código Civil de 2002. São Paulo: Método, 2007. p. 317. 
cláusulas abusivas ou negação de direitos quando vem a necessitar dos serviços prestados pela operadora. Assim, a função social desse contrato perpassa os efeitos que ele terá perante todo o meio social em que as partes estão inseridas e a observação pela operadora de direitos fundamentais dos consumidores, que não podem ser afastados por cláusulas contratuais.

A função social do contrato dos planos de saúde também está diretamente relacionada com a escassez de recursos, com o equilíbrio econômico-financeiro e com a judicialização das demandas. As empresas que iniciam sua participação no mercado de planos de saúde estão sujeitas ao risco do mercado, sendo seguradoras. Entretanto, a insegurança a que estão submetidas muitas vezes é repassada ao consumidor de forma abusiva, com parcelas excessivas e ausência de boa-fé, o que resulta na atuação do Poder Judiciário na tentativa de adaptar as necessidades do consumidor e submeter o contrato à sua função social. ${ }^{52} \mathrm{O}$ Judiciário busca controlar e delinear os limites que devem ser observados pelos agentes no momento e posteriormente à contratação, de forma que não haja quebra da boa-fé ou distanciamento da função social. Nesse aspecto, uma vez que o Poder Executivo é falho em promover políticas públicas que garantam a satisfação de direitos sociais constitucionalmente previstos, o Poder Judiciário enfrenta essa problemática, buscando solucionar casos concretos de negação a direitos. ${ }^{53}$

Um ponto a ser analisado nesse aspecto é a escassez de recursos e a não aplicação do princípio de custo-efetividade mencionado pelo Ministério da Saúde em sua Avaliação Econômica em Saúde. ${ }^{54} \mathrm{O}$ princípio de custo-efetividade objetiva comparar o valor relativo de diferentes intervenções para suprir uma determinada necessidade de saúde, fornecendo informações concretas para que a tomada de decisões na alocação de recursos seja a mais apropriada. Dessa maneira, as operadoras de saúde operariam de uma forma mais segura e os recursos seriam suficientes para a assistência da população. Mesmo o Código de Defesa do Consumidor, no art. $4^{\circ}$, III, propõe uma harmonização entre os interesses do consumidor e o desenvolvimento econômico da nação. A função social do contrato objetiva excluir da relação contratual a atuação do mercado de forma dominadora e prepotente, sem que, por outro lado, se exclua o desenvolvimento econômico. ${ }^{55}$

52 GODOY, Claudio Luiz Bueno de. Função social do contrato. 3. ed. São Paulo: Saraiva, 2009. p. 178.

53 BONIZZATO, Luigi; MARTINS, Flávio Alves. Saúdes pública e privada e relações de consumo: uma análise constitucional e civilística de responsabilidades estatais, pré e pós-contratuais no Brasil. Revista de Direito do Consumidor, São Paulo, v. 23, n. 96, p. 109-138, nov./dez. 2014. p. 112.

54 Disponível em: < http://www.prr4.mpf.gov.br/pesquisaPauloLeivas/arquivos/avaliacao_saude.pdf $>$. Acesso em: 09 mar. 2015. p. 20.

55 THEODORO JÚNIOR, Humberto. O contrato e sua função social. 3. ed. Rio de Janeiro: Forense, 2008. p. 84. 
$\mathrm{Na}$ relação contratual deve se prezar pelo equilíbrio entre a proteção ao consumidor e o bom andamento econômico, uma vez que a insegurança das operadoras do serviço de saúde também resulta em externalidades negativas para a população, que arcará com valores mais altos nas parcelas dos planos contratados, por exemplo. ${ }^{56}$

Hoje existem demandas judiciais de segurados que se submetem aos contratos de adesão de planos de saúde e que, posteriormente, ao realmente necessitarem dos serviços contratados, veem a negativa de seus direitos por restrição contratual. O Superior Tribunal de Justiça decidiu muito recentemente sobre o tema:

\begin{abstract}
AGRAVO REGIMENTAL NO AGRAVO EM RECURSO ESPECIAL. PLANO DE SAÚDE. NULIDADE DE CLÁUSULA CONTRATUAL. TRATAMENTO DE URGÊNCIA. ACOMPANHAMENTO DE RECÉMNASCIDA INTERNADA EM UTI. CUMPRIMENTO FUNÇÃO SOCIAL DO CONTRATO. APLICAÇÃO DO CDC. PRECEDENTES. AGRAVO A QUE SE NEGA PROVIMENTO. 1. A jurisprudência do STJ consolidou-se no sentido de que, ainda que admitida a possibilidade de o contrato de plano de saúde conter cláusulas limitativas dos direitos do consumidor, revela-se abusiva a cláusula restritiva de direito que exclui o custeio dos meios e materiais necessários ao melhor desempenho do tratamento clínico ou do procedimento cirúrgico coberto ou de internação hospitalar. 2. O Tribunal de origem considerou indevida a recusa de cobertura financeira do plano de saúde à autora, ora recorrida, para acompanhar sua filha recémnascida internada em UTI neonatal, visando a manutenção do aleitamento materno. 3. A análise das razões recursais e a reforma do aresto hostilizado, com a desconstituição de suas premissas, impõem reexame de todo âmbito da relação contratual estabelecida e incontornável incursão no conjunto fático-probatório dos autos, o que esbarra nas Súmulas n. 5 e 7 do STJ. 4. Agravo regimental a que se nega provimento.
\end{abstract}

(STJ, AgRg. no AGRAVO EM RECURSO ESPECIAL N. 618.631 - SP. Relator Ministro Luis Felipe Salomão. Data: 20/02/2015).

O STJ decide no sentido de que é lícito às operadoras de plano de saúde limitar os direitos do consumidor nos contratos, estabelecendo, por exemplo, quais doenças estão sendo cobertas, desde que respeitada a lista mínima, de forma que mais serviços serão oferecidos a quem pagar um maior valor, tudo de acordo com a lógica

56 Esse, aliás, um dos princípios do direito de saúde suplementar mencionado acima, qual seja, da defesa do mercado. 
capitalista e de mercado. Porém, a interpretação do Tribunal é no sentido de que é abusiva a negativa da operadora em custear materiais e meios necessários ao melhor desempenho do tratamento da doença coberta pelo plano. Nesse caso, não há afronta ao bom desenvolvimento econômico, apenas houve decisão de abusividade de determinada conduta da operadora de um serviço público e que deve ser declarada nula e retirada do ordenamento jurídico, sob pena de contrariar não só a função social do contrato, mas também a dignidade da pessoa humana.

Nesse sentido, os seguintes arestos:

6.- Com efeito, a conclusão assentada no Tribunal a quo está em sintonia com a jurisprudência desta Corte no sentido de que, se o contrato de plano de saúde prevê a cobertura de determinado tratamento, não podem ser excluídos os procedimentos imprescindíveis para o seu êxito. A propósito, os seguintes precedentes:

DIREITO CIVIL. PLANOS DE SAÚDE. COBERTURA. LIMITAÇÃO CONTRATUAL/ESTATUTÁRIA AO NÚMERO DE SESSÕES DE QUIMIOTERAPIA. IRRETROATIVIDADE DA LEI N. 9.656/98. RELAÇÃO DE CONSUMO. NATUREZAJURÍDICA DA ENTIDADE. DESINFLUÊNCIA. ABUSIVIDADE DA RESTRIÇÃO. I "A relação de consumo caracteriza-se pelo objeto contratado, no caso a cobertura médico-hospitalar, sendo desinfluente a natureza jurídica da entidade que presta os serviços, ainda que se diga sem caráter lucrativo, mas que mantém plano de saúde remunerado". (REsp. 469.911/SP, Rel. Ministro ALDIR Documento: 22199301 - RELATÓRIO E VOTO Site certificado Página 2 de 4 Superior Tribunal de Justiça PASSARINHO JÚNIOR, DJe 10/03/2008).

II - Reconhecida a incidência do Código de Defesa do Consumidor, impende reconhecer, também, a abusividade da cláusula contratual/estatutária que limita a quantidade de sessões anuais de rádio e de quimioterapia cobertas pelo plano. Aplicação, por analogia, da Súmula 302/STJ. Recurso Especial a que se nega provimento. (REsp. 1115588/SP, Rel. Ministro SIDNEI BENETI, TERCEIRA TURMA, julgado em 25/08/2009, DJe 16/09/2009).

Seguro saúde. Cobertura. Câncer de pulmão. Tratamento com quimioterapia. Cláusula abusiva. 1. O plano de saúde pode estabelecer quais doenças estão sendo cobertas, mas não que tipo de tratamento está alcançado para a respectiva cura. Se a patologia está coberta, no caso, o câncer, é inviável vedar a quimioterapia pelo simples fato de ser esta uma das alternativas possíveis para a cura da doença. A abusividade 
da cláusula reside exatamente nesse preciso aspecto, qual seja, não pode o paciente, em razão de cláusula limitativa, ser impedido de receber tratamento com o método mais moderno disponível no momento em que instalada a doença coberta. 2. Recurso especial conhecido e provido. (REsp. 668.216/SP, Rel. Min. CARLOS ALBERTO MENEZES DIREITO, TERCEIRA TURMA, DJ 2.4.07).

Também decide no mesmo sentido o Tribunal de Justiça do Estado de São Paulo:

PLANO DE SAÚDE. Ação cominatória Tratamento psiquiátrico decorrente de surto psicótico - Negativa de cobertura - Restrição contratual alegada - Inadmissibilidade. Incidência do Código de Defesa do Consumidor e da Lei n. 9.656/98 - Abusividade de cláusula reconhecida Necessidade do paciente incontroversa. Afronta à regra do artigo 51, IV e $\S 1^{\circ}$, II, do CDC - Cobertura devida. Exclusão contratual que afrontaria a própria função social do contrato de plano de saúde - Ressarcimento integral determinado. Sentença mantida. Recurso não provido.

(TJ-SP - APL: 10608608720138260100 SP 1060860 87.2013.8.26.0100, Relator: Moreira Viegas. Data de Julgamento: 21/05/2014, 5a Câmara de Direito Privado, Data de Publicação: 21/05/2014).

Nos contratos embasados pelo CDC, a liberdade do juiz em proteger o hipossuficiente é maior e, sendo a saúde um serviço público de tamanha importância, a garantia de todos os meios necessários para a cura do segurado deve ser buscada. $\mathrm{O}$ consumidor, ao contratar com a operadora de serviços privados de saúde, procura uma maior segurança de que terá acesso a todos os procedimentos descritos contratualmente e da melhor maneira possível, contrastando com o que receberia do sistema público de saúde. Nesse sentido, a operadora que se nega a custear um procedimento descrito pelos próprios médicos e que abarca as doenças presentes no contrato, não cumpre a função social desse contrato.

\section{Conclusão}

Os contratos de plano de saúde inserem-se na atuação da iniciativa privada na prestação do serviço de saúde. Trata-se de bem jurídico elevado à categoria de direito social fundamental pela Constituição Federal de 1988, de modo que as controvérsias que envolvam as questões de saúde devem ser analisadas à luz do texto constitucional.

Isso significa ter por diretriz a saúde como dever do Estado e direito de todos, que deve ser garantido mediante políticas sociais e econômicas que visem à 
redução do risco de doença e de outros agravos e ao acesso universal e igualitário às ações e serviços para sua promoção, proteção e recuperação - serviços e ações que são de "relevância pública".

Muito embora se trate de serviço público, é certo que o constituinte não estabeleceu ao Estado um monopólio na execução da atividade, mas facultou à iniciativa particular atuar de forma complementar ou suplementar. Entretanto, embora essa atuação ocorra segundo as regras de direito privado, por meio dos contratos de planos de saúde entre operadoras e consumidores, é certo que ao Poder Público foram atribuídas a regulamentação e fiscalização da prestação do serviço pelas entidades particulares.

No presente caso, coube à Agência Nacional de Saúde essa atribuição, que é feita mediante resoluções, como a Resolução Normativa n. 259/2011 que trata do fechamento dos planos de saúde que não atendem às condições estabelecidas administrativamente.

Em outras palavras, trata-se de controle administrativo feito pela ANS do cumprimento da função social do contrato de plano de saúde, que deve atender a determinadas condições que garantam ao consumidor o acesso à adequada prestação de saúde.

Ainda, o Poder Judiciário é chamado a declarar a nulidade das cláusulas abusivas incorporadas nos contratos de plano de saúde e que representam vantagem excessiva por parte do consumidor. $\mathrm{O}$ controle judicial visa à adequação do contrato à sua função social de garantir ao consumidor a adequada prestação do serviço de saúde, sempre tendo-se por norte tratar-se de direito de todos e direito social fundamental garantido constitucionalmente.

Enquanto as operadoras de planos não atenderem por si mesmas as condições necessárias para prestar de forma adequada o relevante serviço da saúde, as atuações nos âmbitos administrativo e judicial continuarão a ser fundamentais para adequar os contratos de plano de saúde à sua função social.

Ribeirão Preto, abril de 2015.

Referências

ARAGÃO, Alexandre Santos de. Direito dos serviços públicos. 2. ed. Rio de Janeiro: Forense, 2008.

BONIZZATO, Luigi; MARTINS, Flávio Alves. Saúdes pública e privada e relações de consumo: uma análise constitucional e civilística de responsabilidades estatais, pré e pós-contratuais no Brasil. Revista de Direito do Consumidor, São Paulo, v. 23, n. 96, p. 109-138, nov./dez. 2014. 
BOTTESINI, Maury Ângelo; MACHADO, Mauro Conti. Lei dos planos e seguros de saúde. São Paulo: Revista dos Tribunais, 2003.

BRASIL. Leis, Decretos, etc. Constituição Federal, de 5 de outubro de 1988. Brasília: Diário Oficial da União, 1988.

. Leis, Decretos, etc. Lei n. 8.078, de 11 de setembro de 1990. Dispõe sobre a proteção do consumidor e dá outras providências. Brasília: Diário Oficial da União, 1990.

. Leis, Decretos, etc. Lei n. 9.656, de 3 de junho de 1998. Dispõe sobre os planos e seguros privados de assistência à saúde. Brasília: Diário Oficial da União, 1998.

BRASIL. Ministério da Saúde. ANS. Resolução Normativa n. 195, de 14 de julho de 2009. Dispõe sobre a classificação e características dos planos privados de assistência à saúde, regulamenta a sua contratação, institui a orientação para contratação de planos privados de assistência à saúde e dá outras providências. Brasília: Ministério da Saúde, 2009.

DI PIETRO, Maria Sylvia Zanella. Direito administrativo. 25. ed. São Paulo: Atlas, 2012.

FIGUEIREDO, Leonardo Vizeu. Curso de direito de saúde suplementar. 2. ed. Rio de Janeiro: Gen - Forense, 2012.

GLOBEKNER, Osmir Antônio. A saúde entre o público e o privado: o desafio da alocação social dos recursos sanitários escassos. Juruá: Curitiba, 2011.

GODOY, Claudio Luiz Bueno de. Função social do contrato. 3. ed. São Paulo: Saraiva, 2009.

MARQUES, Claudia Lima. Contratos no código de defesa do consumidor: o novo regime das relações contratuais. 6. ed. São Paulo: Revista dos Tribunais, 2011.

MARQUES, Claudia Lima; LOPES, José Reinaldo de Lima; PFEIFFER, Roberto Augusto Castellanos. Saúde e responsabilidade: seguros e planos de assistência privada à saúde. São Paulo: Revista dos Tribunais, 1999.

MENDES, Gilmar Ferreira; BRANCO, Paulo Gustavo. Curso de direito constitucional. 6. ed. São Paulo: Saraiva, 2011.

REALE, Miguel. Função social do contrato. Disponível em: <http://www.miguelreale.com.br/ artigos/funsoccont.htm>. Acesso em: 12 mar. 2015.

RIZZARDO, Arnaldo. Contratos. 13. ed. Rio de Janeiro: Gen - Forense, 2013.

SCHULMAN, Gabriel. Planos de saúde: saúde e contrato na contemporaneidade. Rio de Janeiro: Renovar, 2009.

SERRANO, Mônica de Almeida Magalhães. O Sistema Único de Saúde e suas diretrizes constitucionais. São Paulo: Editora Verbatim, 2009.

SILVA, José Afonso da. Comentário contextual à constituição. 7. ed. São Paulo: Malheiros, 2010. 
TARTUCE, Flávio. Função social dos contratos: do Código de Defesa do Consumidor ao Código Civil de 2002. São Paulo: Método, 2007.

THEODORO JÚNIOR, Humberto. O contrato e sua função social. 3. ed. Rio de Janeiro: Forense, 2008. 